九州大学学術情報リポジトリ

Kyushu University Institutional Repository

\title{
Mixed desorption of $\mathrm{He}, \mathrm{H} \_2$, and $\mathrm{CH} 44$ adsorbed on charcoal maximally cooled at $10 \mathrm{~K}$
}

\section{Fukada, Satoshi}

Department of Advanced Energy Engineering Science, Kyushu University

Terashita, Masashi

Department of Advanced Energy Engineering Science, Kyushu University

ht tp://hdl. hand le. net/2324/26056

出版情報：Journal of Nuclear Science and Technology. 47 (12)，pp.1219-1226，2010-12. 日本原子 力学会

バージョン：

権利関係: (C) Atomic Energy Society of Japan 


\title{
[Article]
}

Mixed desorption of $\mathrm{He}, \mathrm{H}_{2}$, and $\mathrm{CH}_{4}$ adsorbed on charcoal maximally cooled at $10 \mathrm{~K}$

\author{
Satoshi FUKADA*, Masashi TERASHITA \\ Department of Advanced Energy Engineering Science, Kyushu University \\ Hakozaki, Higashi-ku, Fukuoka 812-8581, Japan
}

*Corresponding author

Tel 81-92-642-4140, Fax 81-92-585-6050, Email sfukada@ nucl.kyushu-u.ac.jp

Total page: 25 pages

Text page: 13 pages

Table: 1 page

Figures: 12 pages 


\section{abstract}

Desorption rates of mixtures of $\mathrm{He}, \mathrm{H}_{2}$, and $\mathrm{CH}_{4}$ adsorbed on activated carbon placed in an enclosed vessel are determined under the condition where the temperature is elevated from $10 \mathrm{~K}$ to room temperature. Activated carbon is selected because of its good adsorption performance at the cryogenic temperature. The carbon used in the present study is covered with or mesopores or micropores from $1 \mathrm{~nm}$ to $10 \mathrm{~nm}$ in diameter. The adsorption and desorption of their respective gases proceed independently, and desorption behavior of each component is well expressed in terms of a Langmuir-Freundlich isotherm. Since desorption curves under different heating conditions can be correlated to the same one on a $\left(T-p_{t}\right)$ plot, it is considered that gas desorption proceeds under equilibrium condition between the adsorbent and gaseous phases. Two- or three-component desorption of $\mathrm{He}, \mathrm{H}_{2}$, and $\mathrm{CH}_{4}$ from activated carbon can be described using an extended multicomponent Langmuir-Freundlich isotherm without any correction. Desorption curves calculated for their respective gases are in comparatively good agreement with experimental data.

\section{Keywords:}

cryosoption, activated carbon, tritium, helium, methane, hydrogen 


\section{Introduction}

In a fusion reactor system, the D-T fuel cycle should be established not only to maintain self-sufficient fuel supply but also to meet legal regulations on radiation safety and radiation hygiene, such as the maximum inventory and maximum allowable concentration of tritium in a laboratory room. D-T fuel in a high-temperature plasma chamber is partly burned, and interacts with structural walls such as the first wall and diverter plates. Multicomponent gaseous mixtures including unburned D-T fuel, He, and impurities such as methane, water, and hydrocarbons are exhausted in a lump by evacuation pumps. ${ }^{1,2)}$ Cryosorption pumps for gas evacuation provide an attractive method of recovering the multicomponent gaseous mixture generated in a chamber. All the gases are adsorbed in a lump on an adsorbent cooled at liquid He temperature. The adsorption rate is expected to be very fast, and the ultimate pressure is very low. Therefore, the fuel supply and plasma burning can be operated under clean conditions ${ }^{3)}$ However, the evacuation process is not continuous because of the limit of the adsorption capacity of the cryosorption pump. ${ }^{1,4)}$ The evacuated gas should be regularly desorbed by heating the saturated cryosorption pump, and the desorbed gas is sent to the following fuel purification process using Pd-Ag membrane tubes and catalyst beds. ${ }^{1,3)}$ The desorption process is intermittently operated. However, it is preferable to supply gas to the following fuel purification process continuously. Therefore, several cryosorption pumps are combined and operated in turn. In addition, it is necessary to use a surge tank in order to operate the fuel purification process smoothly. Although the desorption of various gases proceeds selectively at different temperatures ${ }^{5)}$ according to their respective vapor pressures or interaction energies between adsorbent and adsorbate, the information on selective gas desorption from the adsorbent is lost when the desorption gas is stored in a surge tank together. If the information on the selective gas desorption is efficiently utilized in the following fuel purification process, the scale of the fuel purification process, such as the number of Pd-Ag membrane tubes, can be decreased.

In the present study, the selective desorption from a cryosorption pump is investigated experimentally and analytically. Previously, there was some research to investigate processes of adsorption and desorption of a single component of $\mathrm{He}$ or $\mathrm{H}_{2}$ and two-component mixtures on activated carbon utilized for cryosorption pumps. ${ }^{5,6)}$ In addition, the performance of gas adsorption in a large-scale cryosorption pump was experimentally investigated by the ITER group. ${ }^{7,8)}$ The basic adsorption and desorption mechanism and the isotherm of activated carbon for various gaseous molecules were investigated previously. ${ }^{5,6,8,9)}$ However, there is no analytical or experimental study on the adsorption and desorption behavior of multicomponent gas mixtures on the adsorbent. In the present study, experimental results and analytical equations for the three-component gas adsorption 
and desorption of $\mathrm{He}, \mathrm{H}_{2}$, and $\mathrm{CH}_{4}$ are presented. We selected $\mathrm{He}$ and $\mathrm{CH}_{4}$ as representative impurity molecules with high or low vapor pressure that will be generated in plasma chambers and $\mathrm{H}_{2}$ as a representative of D-T fuel. There is less isotope effect in adsorption or desorption on activated carbon among hydrogen isotopes of $\mathrm{H}_{2}, \mathrm{D}_{2}$, and $\mathrm{T}_{2}{ }^{6,7)}$

\section{Experimental}

The experimental apparatus is the same as that shown in our previous study. ${ }^{5,6)}$ The vacuum chamber has a volume of 3.2 L. The chamber is composed of three parts; (i) activated carbon adsorbent that is cooled around at $10 \mathrm{~K}$, (ii) a cryopanel part that is cooled at around $10 \mathrm{~K}$, and (iii) a baffle-panel part cooled around at $80 \mathrm{~K}$. Cooling is performed using two-stage cooling units, which can cool maximally down to $10 \mathrm{~K}$. The cryopanel is coated with a thin activated charcoal film as adsorbent. The temperature is measured using Chromel-AuFe $(0.07 \%)$ thermocouples.

The amount of activated carbon used in the present experiment is $60 \mathrm{~g}$. The specific surface area of the charcoal film is $644 \mathrm{~m}^{2} / \mathrm{g}$, which was determined using a BET specific-surface-area meter (TriStar 3020, Shimadzu corporation). When we use the nitrogen molecular cross-sectional area of $0.162 \mathrm{~nm}^{2}$, the BET specific surface area corresponds to the adsorption amount of $6.6 \mathrm{mmol} / \mathrm{g}$. Figure 1 shows the pore volume distribution of activated carbon used in the present study. The vertical axis is presented in terms of the differential of the cumulative adsorbed amount of nitrogen based on the Barrett-Joyner-Halenda $(\mathrm{BJH})$ method. ${ }^{10)}$ Its values correspond to the pore size distribution with the unit of $\left[\mathrm{cm}^{3}(\mathrm{NTP}) / \mathrm{g}(\mathrm{nm})\right]$. The pore diameter on the horizontal axis, $d_{p}$, is calculated using the sum of the Kelvin equation (the first term of Eq. (1)) and the Halsey equation (its second term) as follows:

$$
d_{p}=2\left[\frac{0.955}{\ln \left(p_{0} / p\right)}+0.354\left\{\frac{5}{\ln \left(p_{0} / p\right)}\right\}^{1 / 3}\right][\mathrm{nm}]
$$

Here, the relative nitrogen pressure at liquid nitrogen temperature is defined as $p / p_{0}$, in which $p_{0}$ $=1.0133 \times 10^{5} \mathrm{~Pa}$. The pore volume determined is distributed in the range from 1.5 to $25 \mathrm{~nm}$ as seen in the figure. The surface area meter used in the present study cannot be used to detect a pore diameter smaller than $1.5 \mathrm{~nm}$. The figure shows that the activated carbon has a large number of mesopores of around $d_{p}=3 \mathrm{~nm}$. Therefore, this material is suitable for the adsorption of small molecules of $\mathrm{He}$ and $\mathrm{H}_{2}$ at the cryogenic temperature.

The total pressure of the vacuum chamber is detected using two absolute-pressure gauges 
(Baratron capacitance manometers, MKS Instruments). The different ranges of manometers make it possible to measure at a range from $10^{-3}$ to $10^{3} \mathrm{~Pa}$. Another ionization gauge is used to detect pressure under vacuum. The ultimate pressure measured in the system is $10^{-5} \mathrm{~Pa}$. A mechanical booster pump (MBS 303, ULVAC corporation) is used for roughing evacuation. The residual gas is measured using a quadrupole mass spectrometer (BGM-101, ULVAC), which is evacuated using a turbomolecular pump (UTM-150, ULVAC). In order to keep the material balance correctly, however, the residual gas meter and ionization gauge were not used during the desorption experiment. The total pressure only is measured using the capacitance manometer during the temperature elevation for gas desorption. The residual gas is analyzed before and after the temperature elevation.

An experiment is performed using the following procedures: (i) A vacuum chamber is evacuated using the mechanical booster pump. (ii) A single component of $\mathrm{He}, \mathrm{H}_{2}$, or $\mathrm{CH}_{4}$ or a two- or three-component mixture is introduced under conditions of a specified partial (and total) pressure and room temperature. (iii) Cooling of the cryosorption pump is started, and the total pressure and temperature are recorded. (iv) After the system has been sufficiently cooled to $10 \mathrm{~K}$ and the pressure has achieved a steady-state ultimate value, cooling of the cryosorption pump is cut off. (v) The increments of temperature and total pressure are recorded. No gas evacuation is carried out during the temperature elevation period. (vi) The temperature elevation is controlled using a band heater curled around the shell of the cryosorption pump. The temperature of the heater can be elevated maximally at $70^{\circ} \mathrm{C}$. (vii) Desorbed gas in the system is analyzed using the quadrupole mass spectrometer. (viii) Then, the experiment of adsorption and desorption is repeated under another experimental condition.

\section{Analysis}

\section{Material balance in evacuation vessel}

Under an initial condition before cooling, an enclosed chamber volume $v$ is filled with an ideal gas mixture of $k$-component partial pressure, $p_{k, 0}\left(k=\mathrm{He}, \mathrm{H}_{2}\right.$ and $\left.\mathrm{CH}_{4}\right)$, and temperature of $T_{\text {room }}$. The molar amount $n_{k, 0}$ for each of the $k$ components is determined as follows:

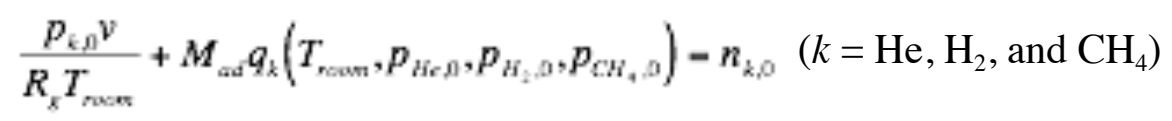

The total molar amount of gas introduced initially in the chamber, $n_{t, 0}$, and the total pressure, $p_{t, 0}$, are the sum of each component as follows:

$$
n_{t, \Omega}=n_{H \in O}+n_{H_{2}, \mathrm{O}}+n_{C H_{4},} \quad(3)
$$




$$
p_{i, 0}=p_{B \in, 0}+p_{H_{1}, 0}+p_{C H_{1}, \mathrm{O}}
$$

When the chamber is evacuated using a cryosorption pump, the material balance of the mixed gaseous components in the enclosed chamber and pump at arbitral temperature of $T$ is described as follows:

$$
\frac{p_{k} v_{C}}{R_{g} T}+\frac{p_{k}\left(v-v_{C}\right)}{R_{g} T_{\text {rose }}}+M_{a j} q_{k}\left(T, p_{H e}, p_{H_{4}}, p_{C H_{4}}\right)-n_{k, O} \quad\left(k=\mathrm{He}, \mathrm{H}_{2} \text {, and } \mathrm{CH}_{4}\right) \text { (5). }
$$

The total pressure under the arbitral cooled condition, $p_{t}$, is the sum of the partial pressures for each component under respective conditions as follows:

$$
p_{i}=p_{i t}+p_{H_{2}}+p_{C H_{4}}
$$

The molar fraction of the $k$ component at the arbitral cooled condition, $x_{k}$, and its value at the initial condition, $x_{k, 0}$, are defined as follows:

$$
\begin{array}{ll}
x_{k}=\frac{p_{k}}{p_{t}} & \left(k=\mathrm{He}, \mathrm{H}_{2}, \text { and } \mathrm{CH}_{4}\right) \\
x_{k, 1}=\frac{p_{k, \Omega}}{p_{t \Omega 0}} & \left(k=\mathrm{He}, \mathrm{H}_{2}, \text { and } \mathrm{CH}_{4}\right)
\end{array}
$$

For the activated carbon used in the present study, the second term on the left-hand side in Eq. (2) is negligibly small. Therefore, the term is regarded as zero in the analysis described below. Thus, the combination of Eqs. (1)-(7) results in the equation:

$$
\left(\frac{1}{T_{R}} \frac{v_{C}}{v}+\frac{v-v_{C}}{v}\right) p_{R} x_{k}+\frac{M_{a d}}{n_{i, \Omega}} q_{k}\left(T, p_{k i}, p_{R_{2}}, p_{C K_{4}}\right)-x_{k, 0} \quad\left(k=\mathrm{He}, \mathrm{H}_{2} \text {, and } \mathrm{CH}_{4}\right)(9),
$$

where $p_{R}$ and $T_{R}$ are the normalized total pressure and temperature defined as follows:

$$
\begin{aligned}
& p_{R}=\frac{p_{i}}{p_{t, 0}} \quad \text { (10), } \\
& T_{g}=\frac{T}{T_{\text {ras }}} \quad \text { (11). }
\end{aligned}
$$

Thus, the dimensionless pressure and temperature are normalized using their respective values under the initial condition and are defined in the ranges of $0 \leq p_{R} \leq 1$ and $0 \leq T_{R} \leq 1$.

\section{Single-component adsorption and desorption}

When a single component gas is initially introduced in the cryosorption pump, the values of $x_{k}$ and $x_{k, 0}$ are always equal to unity in Eq. (8). Consequently, the following material balance equation of a single component in the enclosed chamber is valid:

$$
\frac{M_{a+1}}{n_{i, 0}} q_{k}\left(T, p_{k}\right)-1-p_{R}\left(\frac{1}{T_{R}} \frac{v_{C}}{v}+\frac{v-v_{C}}{v}\right) \quad\left(k=\mathrm{He}, \mathrm{H}_{2}, \text { and } \mathrm{CH}_{4}\right)
$$


When equilibrium is achieved between a gas phase and an adsorbed phase, $q_{k}\left(T, p_{k}\right.$ ) is described using an adsorption isotherm. Then, the adsorption (or desorption) isotherm for each single component, $q_{k}\left(T, p_{k}\right)$, can be determined from the experimental $\left(T-p_{k}\right)$ relation (or the normalized $\left(T_{R}-p_{R}\right)$ relation) and Eq. (12). It is assumed in the present study that the adsorption (or desorption) isotherm of the single component, $q_{k}\left(T, p_{k}\right)$, can be correlated to the Langmuir-Freundlich relation proposed by Sips: ${ }^{11)}$

$$
q_{k}\left(T, p_{k}\right)-q_{k, \alpha} \frac{K_{k} p_{k}^{n_{i}} \exp \left(\frac{E_{k}}{R_{g} T}\right)}{1+K_{k} p_{k}^{n_{+}} \exp \left(\frac{E_{k}}{R_{g} T}\right)} \quad\left(k=\mathrm{He}, \mathrm{H}_{2} \text {, and } \mathrm{CH}_{4}\right)
$$

The experimental history of an adsorption-desorption process on the $\left(T-p_{k}\right)$ plane and the combination of Eqs. (12) and (13) can give the values of the parameters included in the adsorption (or desorption) isotherm of Eq. (13), $K_{k}, E_{k}$ and $n_{k}$. The values determined for $\mathrm{He}, \mathrm{H}_{2}$, and $\mathrm{CH}_{4}$ are given in Table 1.

\section{Multicomponent adsorption and desorption}

The above single-component isotherm, Eq. (13), is extended to the case of multicomponent adsorption. For the multicomponent adsorption or desorption of gaseous mixtures composed of He, $\mathrm{H}_{2}$, and $\mathrm{CH}_{4}$, the following extended Langmuir-Freundlich relation is assumed here:

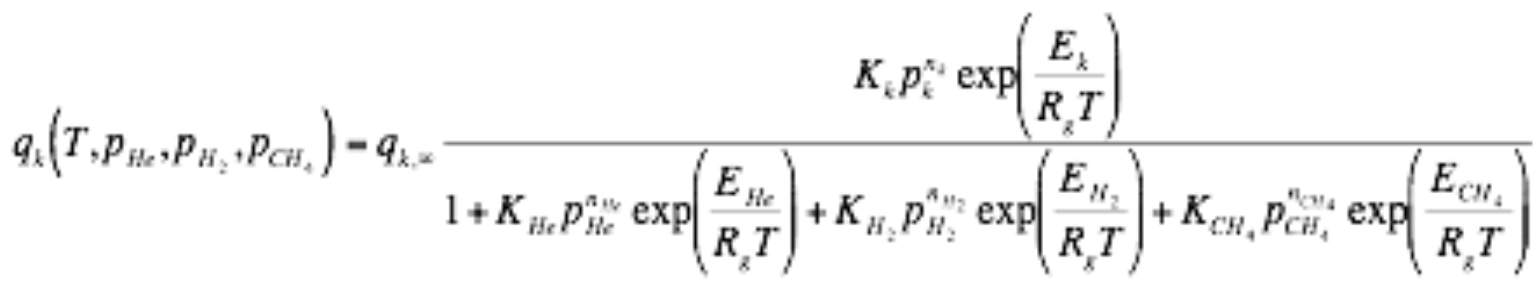

$$
\begin{aligned}
& \left(k=\mathrm{He}, \mathrm{H}_{2} \text { and } \mathrm{CH}_{4}\right) \quad \text { (14). }
\end{aligned}
$$

Eq. (14) is deduced from a material balance on the surface under the condition where three gases are adsorbed on the same site and there is no interaction among the adsorbed gases except for combining energy between the adsorbent and adsorbate. When competitive adsorption proceeds among a multicomponent gaseous mixture, the adsorption amount of the $k$ component is a function of not only the partial pressure of the corresponding $k$ component but also those of other components. There is no additional parameter in Eq. (14) except the parameters determined from each isotherm of a single component. In other words, there is no correction in Eq. (14), and the isotherm of multicomponent mixtures can be determined automatically from that of the single component.

If each of gases adsorbed and desorbed behaves independently, the isotherm for the 
three-component mixture of $\mathrm{He}, \mathrm{H}_{2}$ and $\mathrm{CH}_{4}$, Eq. (14), can be approximated using the following simplified equation similar to a single-component isotherm:

$$
q_{k}\left(T, p_{t}, x_{k}\right)=q_{k, x} x_{k, 0} \frac{K_{k} p_{t}^{\varepsilon_{k}} x_{k}^{\varepsilon_{k}} \exp \left(\frac{E_{k}}{R_{g} T}\right)}{1+K_{k} p_{t}^{n_{k}} x_{k}^{n_{k}} \exp \left(\frac{E_{k}}{R_{g} T}\right)} \quad\left(k=\mathrm{He}, \mathrm{H}_{2}, \text { and } \mathrm{CH}_{4}\right)
$$

\section{Results and Discussion}

\section{Single-component desorption}

Figure 2 shows experimental data for the desorption of a single component gas $\left(\mathrm{He}, \mathrm{H}_{2}\right.$, or $\mathrm{CH}_{4}$ ) adsorbed on activated carbon in the process of heating from $10 \mathrm{~K}$ to room temperature. The vertical axis is pressure and the horizontal axis is temperature. The left and bottom values are normalized using appropriate respective initial conditions, and the right and top ones are raw values. The initial pressure of gas introduced to the chamber is constant $\left(p_{t, 0}=100 \mathrm{~Pa}\right)$ throughout the present experiment. When the adsorbed gas has been completely desorbed during the temperature elevation, each desorption curve approaches a single nonadsorption curve, which means $q_{k}\left(T, p_{k}\right)=0$ in Eq. (5) or (9). Consequently, the relation of $1-\left(p_{r}\right)_{\text {sadiorsiox }}\left(\frac{1}{T} \frac{v_{C}}{v}+\frac{v-v_{C}}{v}\right)-0$ from Eq. (9) is obtained under the nonadsorption condition. The nonadsorption curve shown by a broken line in the figure is independent of gaseous species in the case of ideal gas. The adsorbed amount on the activated carbon can be determined from the difference between the nonadsorption and adsorption conditions.

Figures 3(a) and (b) comparatively show desorption curves for two different temperature elevation rates for $\mathrm{He}$ and $\mathrm{CH}_{4}$, respectively. The desorption proceeds differently for each gas depending on the temperature elevation rate. Since the limit of the maximum allowable temperature of welding used in the present cryosorption pump is $70^{\circ} \mathrm{C}$, the temperature elevation rate cannot be changed widely. The gas amount adsorbed per unit activated carbon remains constant immediately after the temperature elevation, because the gas amount introduced to the chamber is constant as $n_{k, 0}$ $=1.31 \times 10^{-4} \mathrm{~mol}\left(2.95 \mathrm{~cm}^{3}(\mathrm{NTP})\right)$ for any $\mathrm{k}$ component $\left(k=\mathrm{He}, \mathrm{H}_{2}\right.$, and $\left.\mathrm{CH}_{4}\right)$ throughout the experiment. When desorption is initiated, the amount adsorbed on charcoal decreases according to the temperature elevation.

The adsorbed amounts for the two different heating rates are plotted as a function of temperature in Fig. 4. As seen in the figure, there are hardly any changes in the desorption curves 
regardless of the different temperature increment rates. This tendency was the same for gases of He, $\mathrm{H}_{2}$, and $\mathrm{CH}_{4}$. This is because the desorption proceeds under an equilibrium condition. Therefore, we can determine the isotherm of $q_{k}\left(T, p_{k}\right)$ from a desorption history during the heating process.

Figure 5 shows the normalized adsorption amount on the left axis, $M_{a d} q_{k}\left(T, p_{k}\right) / n_{t, 0}$, as a function of the normalized temperature on the bottom axis, $T_{R}$. The values of respective raw data are on the right axis and the top axes. Almost every gas introduced in the system is adsorbed at the cryogenic temperature. Consequently, the $p_{R}$ value becomes zero when $T_{R}$ is very low, as seen in Fig. 2. Therefore, the $M_{a d} q_{k}\left(T, p_{k}\right) / n_{t, 0}$ value of Fig. 5 becomes unity when $T_{R}$ approaches zero. On the other hand, $p_{R}$ becomes unity from the initial condition when $T_{R}$ approaches unity, and therefore, the $M_{a d} q_{k}\left(T, p_{k}\right) / n_{t, 0}$ value becomes zero. The values of the parameters included in the isotherm were determined for their respective gases from fitting calculations to the experimental data of Fig. 5 and are tabulated in Table 1. The pressure dependence for He desorption is determined based on previous studies of He adsorption isotherm on activated carbon, ${ }^{12,13)}$ the pressure index in the isotherm for $\mathrm{He}, n_{\mathrm{He}}$, is assumed to be 0.2 . The pressure index for the $\mathrm{H}_{2}$ or $\mathrm{CH}_{4}$ adsorption is assumed to be unity in this pressure region judging from previous papers. ${ }^{14,15)}$ The adsorption heat is almost coincident with previous studies. ${ }^{12-16)}$

\section{Multi-component desorption}

The 2- or 3-component gaseous mixtures of $\mathrm{He}, \mathrm{H}_{2}$, and $\mathrm{CH}_{4}$ with specified compositions are introduced into the vacuum chamber at a total pressure of $p_{t, 0}(100 \mathrm{~Pa})$ and are cooled. Figures 6(a), 6(b) and 6(c) show variations of the normalized total adsorption amount of $M_{a d} q_{t}\left(T, p_{H e}, p_{H 2}\right.$, $\left.p_{C H 4}\right) / n_{t, 0}$ on the left axis with $T_{R}$ on the bottom axis for different combinations of the two-component gas mixtures. The values of the right and top axes are original data before normalization. The broken lines are calculation results using Eq. (14). Figure 7 shows variations of the $M_{a d} q_{t}\left(T, p_{H e}, p_{H 2}\right.$, $\left.p_{C H 4}\right) / n_{t, 0}$ value on the left axis with $T_{R}$ on the bottom axis for the three-component gas mixtures. The initial molar fraction of $x_{k, 0}$ and the initial partial pressure of $p_{k, 0}$ are determined from pressure change when each gas is introduced. The initial molar fraction was coincident with the values measured by the mass spectrometer after gas desorption. Regardless of the combinations of $\mathrm{He}, \mathrm{H}_{2}$, and $\mathrm{CH}_{4}$, comparatively good agreement is obtained between experiment and calculation. The temperatures at the time when desorption starts are $20 \mathrm{~K}$ for $\mathrm{He}, 75 \mathrm{~K}$ for $\mathrm{H}_{2}$, and $180 \mathrm{~K}_{\text {for }} \mathrm{CH}_{4}$, and are independent of the presence of other gas components. The coverage of the adsorption site in the present experiment is estimated around at $3 \times 10^{-4}$. The behavior of independent adsorption may come from the small coverage. Application of the single-component Langmuir-Freundlich isotherm to the multicomponent one can be made without introduction of any additional parameter. Small 
differences seen in the comparison between the experiment and calculation in Figs. 5(a), 5(b), 5(c) and 6 will be clarified in a future experiment carried out under wider range conditions.

Figure 8 shows desorption rates, $d p_{R} / d t$, which are determined from the differential of experimental pressure change. The three peaks seen in the rate curve correspond to the gas desorptions of $\mathrm{He}, \mathrm{H}_{2}$, and $\mathrm{CH}_{4}$. This figure clearly shows how the three gases are desorbed independently. As a result of numerical fitting, it was found that the desorption rate for the three-component gas mixtures can be approximated by the combination of three Gaussian distribution curves as follows:

$$
\frac{d p_{i}}{d T}=\sum_{k=\mu_{l}, H_{2} c H_{4}} \frac{p_{k,-}}{\sqrt{2 \pi} \sigma_{k}} \exp \left[-\frac{\left(T-T_{k}\right)^{2}}{2 \sigma^{2}}\right]
$$

In addition, the relation of $\frac{d p_{k}}{d t}-\left(\frac{d p_{k}}{d T}\right)\left(\frac{d T}{d t}\right)$ is used for the calculation on the $\left(d p_{R} / d t-T\right)$ plot. All those results indicate that $\mathrm{He}, \mathrm{H}_{2}$, and $\mathrm{CH}_{4}$ are adsorbed and desorbed on activated carbon at the cryogenic temperature independently.

\section{Release of residual gas by heating}

It is important to study how other residual gaseous components affect adsorption or desorption on activated carbon. The effect of residual gas is especially important for tritium evacuation. ${ }^{17)}$ An experiment to investigate the effect of residual gas on the adsorption and desorption of a multicomponent gas is carried out under the following condition. The cryosorption pump is supplied with a mixture of $\mathrm{He} 50 \mathrm{~Pa}$ and $\mathrm{CH}_{4} 50 \mathrm{~Pa}$ at room temperature, the system is then cooled to $10 \mathrm{~K}$, and the multicomponent gas is desorbed during temperature elevation until room temperature. Next, the desorbed gas is evacuated to $10^{-1} \mathrm{~Pa}$ using the mechanical booster pump for roughing evacuation. Then, $100 \mathrm{~Pa} \mathrm{H}_{2}$ is supplied at room temperature. The system is cooled in a similar way and is desorbed by temperature elevation up to $50^{\circ} \mathrm{C}$ using the band heater. The desorption curve during the last heating process is shown in Fig. 9 on a logarithmic scale.

As seen in the figure, at first, a small He peak and then a large $\mathrm{H}_{2}$ peak appear with temperature elevation. The peak area of $\mathrm{He}$ is around $1 / 200$ of that of $\mathrm{H}_{2}$. Then, the peaks of $\mathrm{CH}_{4}, \mathrm{~N}_{2}$, and $\mathrm{O}_{2}$ emerge at around $150 \mathrm{~K}$. The peak of $\mathrm{CH}_{4}$ is a little larger than that of He. This is because a small amount of $\mathrm{CH}_{4}$ remained in the adsorbed site of the activated carbon at room temperature regardless of evacuation using the external roughing pump. In the latter desorption process, the system is not evacuated from the outside. Consequently, there is possibility that a small amount of $\mathrm{CH}_{4}$ is still adsorbed on the activated carbon at room temperature. It was found that the residual $\mathrm{CH}_{4}$ amount 
corresponds to around one percent of the supplied gas. The $\mathrm{CH}_{4}$ supplied initially is desorbed following temperature elevation up to room temperature. $\mathrm{N}_{2}$ and $\mathrm{O}_{2}$ are also desorbed in the same temperature range. The peak ratio of $\mathrm{N}_{2}: \mathrm{O}_{2}$ is around $4: 1$, and therefore it is considered that their origin comes from a small air leak from the outside. On the other hand, $\mathrm{He}, \mathrm{H}_{2}, \mathrm{O}_{2}$, and $\mathrm{N}_{2}$ peaks do not show any increase after the temperature elevation until $50^{\circ} \mathrm{C}$. Heating above $70^{\circ} \mathrm{C}$ is not allowed in the present experiment, because of the protection of the thermocouples used here. The adsorption forces of these molecules to the activated carbon are very weak. $\mathrm{CH}_{4}$ shows a small increase after heating. $\mathrm{H}_{2} \mathrm{O}$ is the main molecule that shows a certain increase in the residual gas during heating. The $\mathrm{H}_{2} \mathrm{O}$ peak apparently increases after the temperature elevation. Therefore, the main residual gas component remaining on the activated carbon is considered to be $\mathrm{H}_{2} \mathrm{O}$. Our result that $\mathrm{H}_{2} \mathrm{O}$ remains on the activated carbon coincides with the previous research by Day et al. ${ }^{18)}$ A certain amount of $\mathrm{H}_{2} \mathrm{O}$ remains even after room temperature. Therefore pretreatment heating at around $250^{\circ} \mathrm{C}$ and evacuation by another roughing pump ${ }^{17)}$ are necessary to remove a small amount of $\mathrm{H}_{2} \mathrm{O}$ adsorbed on the activated carbon.

\section{Conclusions}

$\mathrm{He}, \mathrm{H}_{2}$, and $\mathrm{CH}_{4}$ were independently adsorbed and desorbed on activated carbon from $10 \mathrm{~K}$ to room temperature. Their desorption isotherms for single-component, two-component and three-component gases are expressed using an extended Langmuir-Freundlich isotherm. The multicomponent desorption profiles of $\mathrm{He}, \mathrm{H}_{2}$, and $\mathrm{CH}_{4}$ were predicted comparatively correctly based on the single-component adsorption isotherm. The activated carbon including a pore volume of around $1 \mathrm{~nm}$ works well for $\mathrm{He}$ and $\mathrm{H}_{2}$ adsorption at the cryogenic temperature. Selective desorption behavior by a cryosorption pump can be utilized for the simple separation of plasma exhaust gas including unburned fuel, $\mathrm{He}$ and impurities before sending the exhaust gas to the following fuel purification system of a fusion reactor system. Although residual gases of $\mathrm{CH}_{4}, \mathrm{~N}_{2}$, and $\mathrm{O}_{2}$ were observed during temperature elevation to room temperature, those gases can be desorbed by using the external evacuation pump. Heating of the cryosorption pump until $250^{\circ} \mathrm{C}$ is necessary for the complete desorption of $\mathrm{H}_{2} \mathrm{O}$ preadsorbed on activated carbn.

\section{Nomenclature}

$E_{k} \quad$ adsorption heat for $k$ component $[\mathrm{J} / \mathrm{mol}]$

$K_{k} \quad$ adsorption constant in equilibrium isotherm for $k$ component $\left[1 / \mathrm{Pa}^{\mathrm{n}}\right]$ 


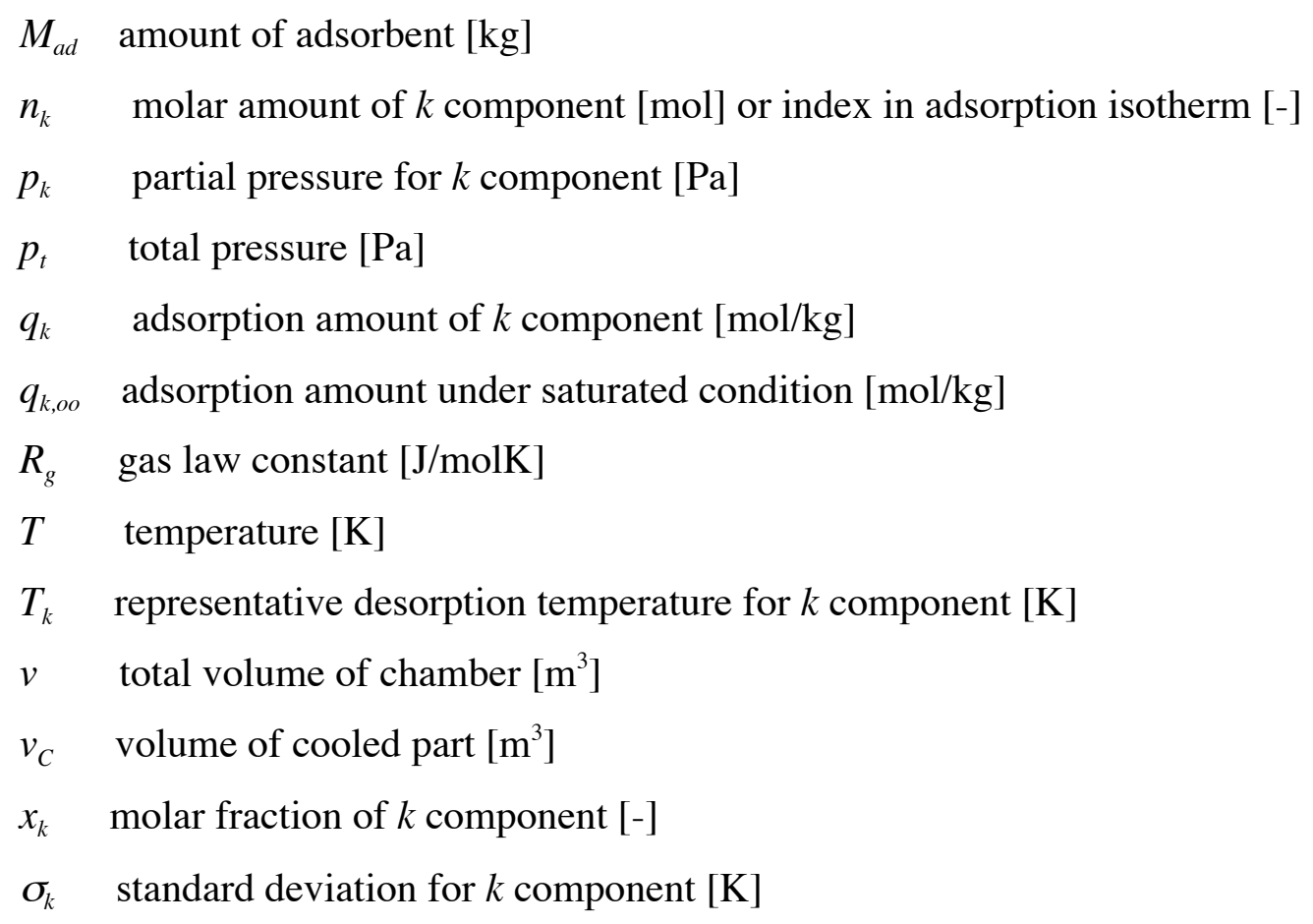

\section{Subscripts}

$k \quad$ gaseous component

$R \quad$ relative condition to initial one

$0 \quad$ initial condition

room room condition

\section{Acknowledgements}

This research is financially supported partly by Grants-in-Aids for Scientific Research in Priority Area on Tritium Science and Technology for Fusion Reactor (contract no. 19055006) and partly by Large Helical Device Coordinated Research of National Institute for Fusion Science (contract no. NIFS07KOBS010).

\section{References}

1) M. Glugla, D. K. Murdoch, A. Antipenkov, S. Beloglazov, I. Cristescu, I.-R. Cristescu, C. Day, R. Laesser, A. Mack, "ITER fuel cycle R\&D: Consequences for the design”, Fusion Eng. Des., 81 (2006) 733-744.

2) C. Day, A. Mack, M. Glugla, D. K. Murdoch, "Tritium inventories in the high vacuum pumps of ITER", Fusion Sci. Technol., 41 (2002) 602-606.

3) C. Day, D. Murdoch, “The ITER vacuum systems”, J. Phys. Conf. Series, 114 (2008) 012013. 
4) M. Wykes, "Minimization of the hydrogenic inventory of the ITER neutral beam line and torus cryosorption pumps", Fusion Sci. Technol., 48 (2005) 39-42.

5) S. Fukada, M. Terashita, "Behavior of desorption of hydrogen, helium and impurities from cryosorption pump", Fusion Sci. Technol., 57 (2010) 112-119.

6) M. Terashita, S. Fukada, "Experimental clarification on desorption behavior of $\mathrm{H}_{2}, \mathrm{D}_{2}$ and $\mathrm{He}$ mixtures from cryo-sorption pump", the result was presented in ICFRM-14 and the paper is contributed to J. Nucl. Mater.

7) C. Day, D. Brennan, P. Camp, H. S. Jensen, G. Jones, A. Mack, A. Miller, "Performance of ITER-relevant cryopump panel for triated gases", Fusion Sci.Technol., 48 (2005) 29-34.

8) C. Day, “The use of active carbons as cryosorbent", Colloids and Surfaces, 187-188 (2001) 187-206.

9) K. Mohanty, D. Das, M. N. Biswas, "Preparation and characterization of activated carbons from sterculia alata nutshell by chemical activation with zinc chloride to remove phenol from wastewater", Adsorption, 12 (2006) 119-132.

10) R. T. Yang, “Adsorbents: fundamentals and applications", John Wiley and Sons, (2003).

11) R. Sips, "On the structure of a catalytic surface", J. Chem. Phys., 16 (1948) 490-495.

12) M. Kumita, J. Ozaki, J. Kobayashi, M. Ito, F. Watanabe, M. Hasatani, "Characteristics of helium adsorption on microporous solids under cryogenic conditions", J. Chem. Eng. Japan, 28 (1995) 159-164.

13) N. Setoyama, K. Kaneko, F. Rodriguez-Reinoso, "Ultramicropore characterization of microporous carbons by low-temperature helium adsorption", J. Phys. Chem., 100 (1996) 10331-10336.

14) L. L. Vasiliev, L. E. Kanonchik, A. G. Kulakov, D. A. Mishkins, P. Brovka, “Activated carbon and hydrogen adsorption storage", Hydrogen materials science and chemistry of carbon nanomaterials, (2007) 633-651.

15) F. V. S. Lopes, C. A. Grande, A. M. Ribeiro, J. M. Loureiro, O. Evaggelos, V. Nikolakis, A. E. Rodrigues, "Adsorption of $\mathrm{H}_{2}, \mathrm{CO}_{2}, \mathrm{CH}_{4}, \mathrm{CO}, \mathrm{N}_{2}$ and $\mathrm{H}_{2} \mathrm{O}$ in activated carbon and zeolite for hydrogen production", Sep. Sci. Technol., 44 (2009) 1045-1073.

16) Y. Kawamura, M. Enoeda, R. S. Willms, P. M. Zielinski, R. H. Wilhelm, M. Nishi “Adsorption isotherms for tritium on various adsorbents at liquid nitrogen temperature", Fusion Technol., 37 (2000) 54-61.

17) A. I. Vedeneev, M. V. Glagolev, N. T. Kazakovskiy, V. N. Labanov, I. L. Malkov, S. A. Pimanikhin, G. L. Saksaganskiy, "Research into tritium impact on the models of cryosorption panels under conditions simulating operation of a vacuum pump of fusion reactors", Fusion Eng. 
Des., 58-59 (2001) 355-357.

18) C. Day, B. Kammerer, A. Mack, "The influence of water on the performance of ITER cryosorption vacuum pumps", Fusion Eng. Des., 51-52 (2000) 229-235. 
Table 1 Adsorption parameters of Langmuir-Freundlich isotherm for $\mathrm{He}, \mathrm{H}_{2}$, and $\mathrm{CH}_{4}$

\begin{tabular}{|c|c|c|c|}
\hline & $\mathrm{He}$ & $\mathrm{H}_{2}$ & $\mathrm{CH}_{4}$ \\
\hline$n_{k}$ & 0.2 & 1.0 & 1.0 \\
\hline$E_{k}$ & $1.75 \mathrm{~kJ} / \mathrm{mol}$ & $14.0 \mathrm{~kJ} / \mathrm{mol}$ & $44.8 \mathrm{~kJ} / \mathrm{mol}^{-1} \mathrm{~Pa}^{-1}$ \\
\hline$K_{k}$ & $1.97 \times 10^{-3} \mathrm{~Pa}^{-0.2}$ & $6.16 \times 10^{-9} \mathrm{~Pa}^{-1}$ & $5.49 \times 10^{-12}$ \\
\hline
\end{tabular}




\section{Figure Captions}

Fig. 1 Pore volume distribution of activated charcoal

Fig. 2 Variations of pressure and temperature for gas desorption from cryosorption pump

Fig. 3 Desorption curves under different temperature increase conditions

Fig. 4 Gas desorption profiles from activated carbon under different heating conditions

Fig. 5 Experimental desorption profiles for $\mathrm{He}, \mathrm{H}_{2}$, and $\mathrm{CH}_{4}$ from activated carbon and curves calculated from Langmuir-Freundlich isotherm

Fig. 6(a) Desorption of $\mathrm{H}_{2}+\mathrm{He}$ mixtures from activated charcoal

Fig. 6(b) Desorption of $\mathrm{He}+\mathrm{CH}_{4}$ mixtures from activated carbon

Fig. 6(c) Desorption of $\mathrm{H}_{2}+\mathrm{CH}_{4}$ mixtures from activated carbon

Fig. 7 Desorption of $\mathrm{He}+\mathrm{H}_{2}+\mathrm{CH}_{4}$ mixtures from activated carbon

Fig. 8 Desorption rates of $\mathrm{He}, \mathrm{H}_{2}$ and $\mathrm{CH}_{4}$ mixtures from active carbon

Fig. 9 Release of residual gas from activated carbon during heating 


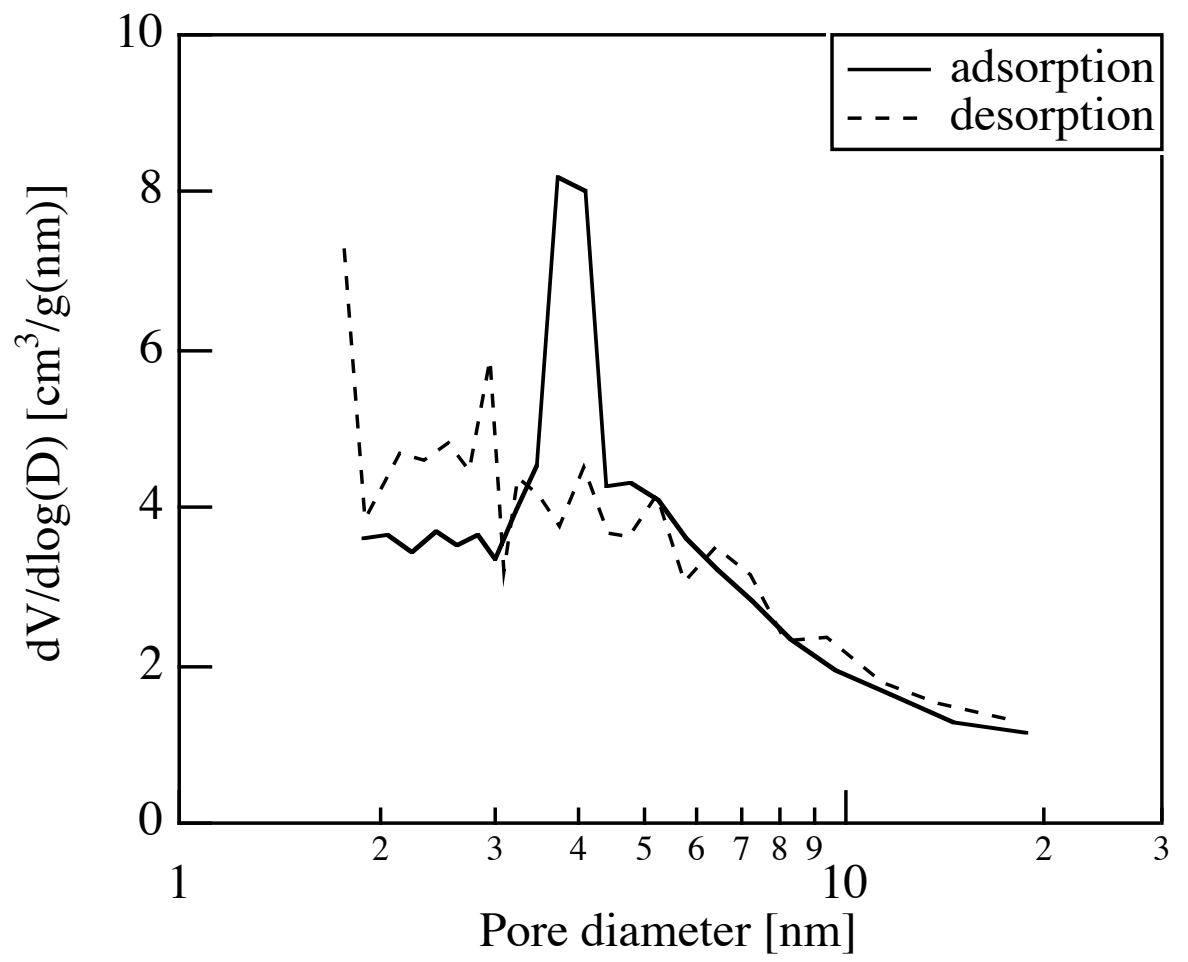

Fig. 1 Pore volume distribution of activated carbon 


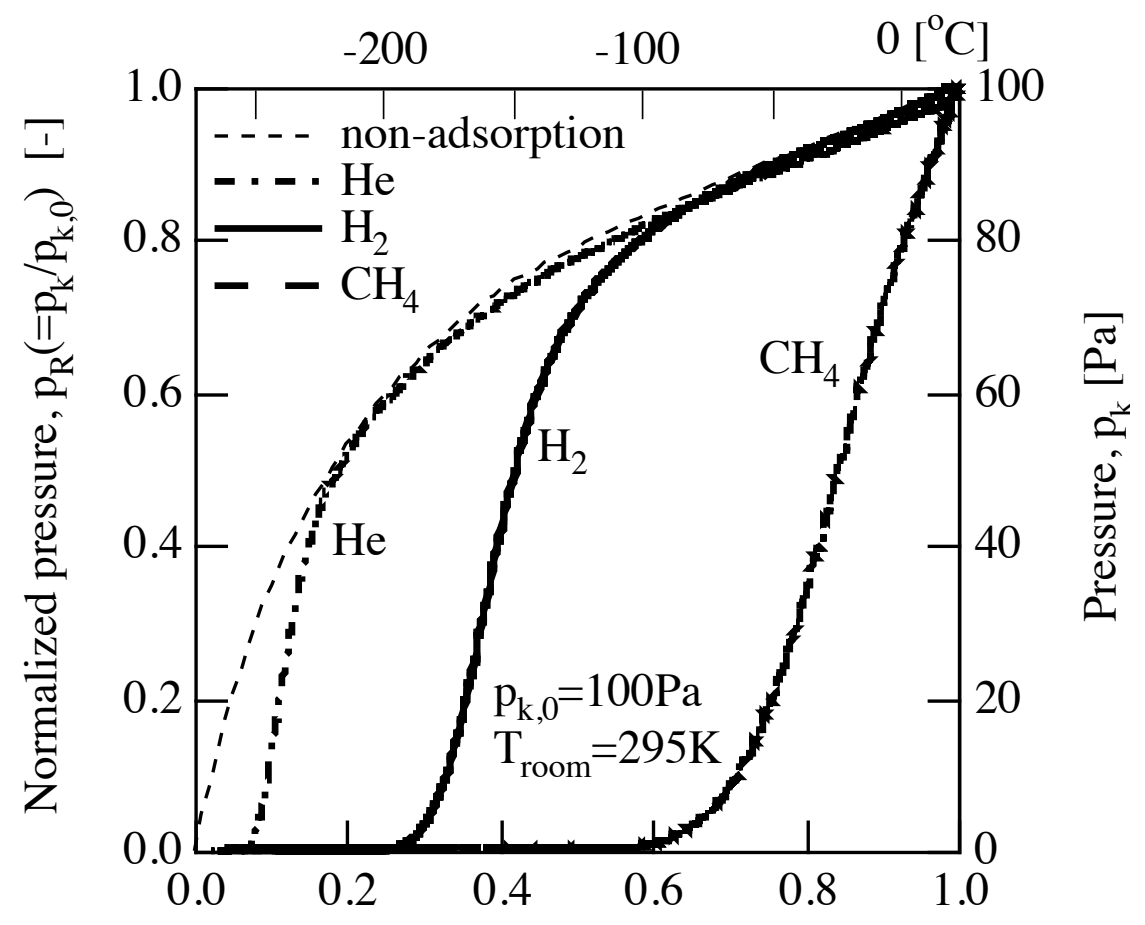

Normalized temperature, $\mathrm{T}_{\mathrm{R}}\left(=\mathrm{T} / \mathrm{T}_{\text {room }}\right)[-]$

Fig. 2 Variations of pressure and temperature for gas desorption from cryosorption pump 


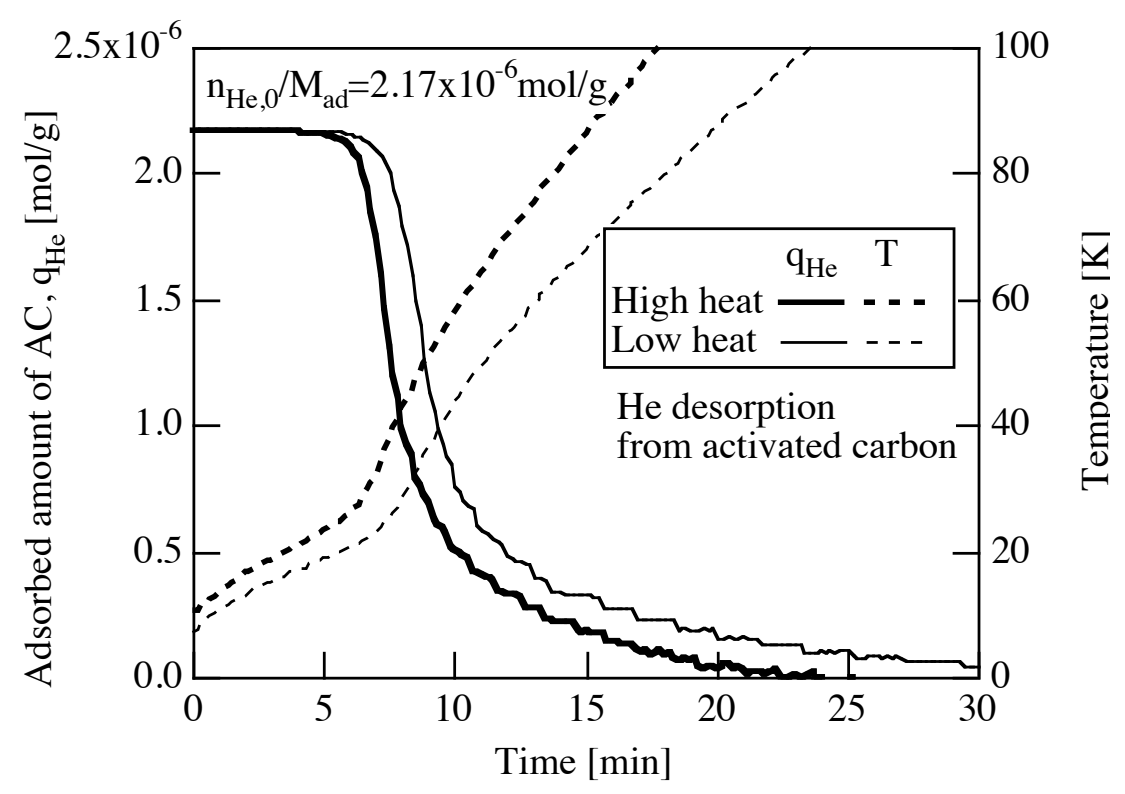

(a) He desorption curves

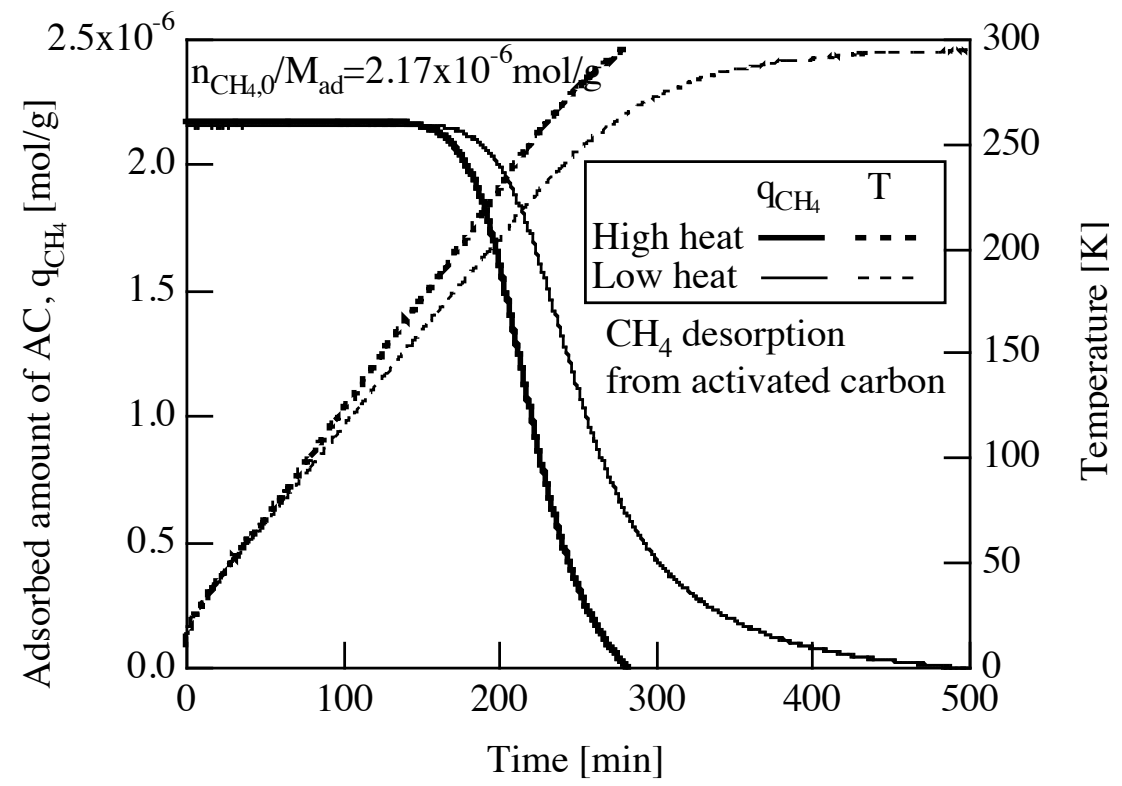

(b) $\mathrm{CH}_{4}$ desorption curves

Fig. 3 Desorption curves under different temperature increase conditions 


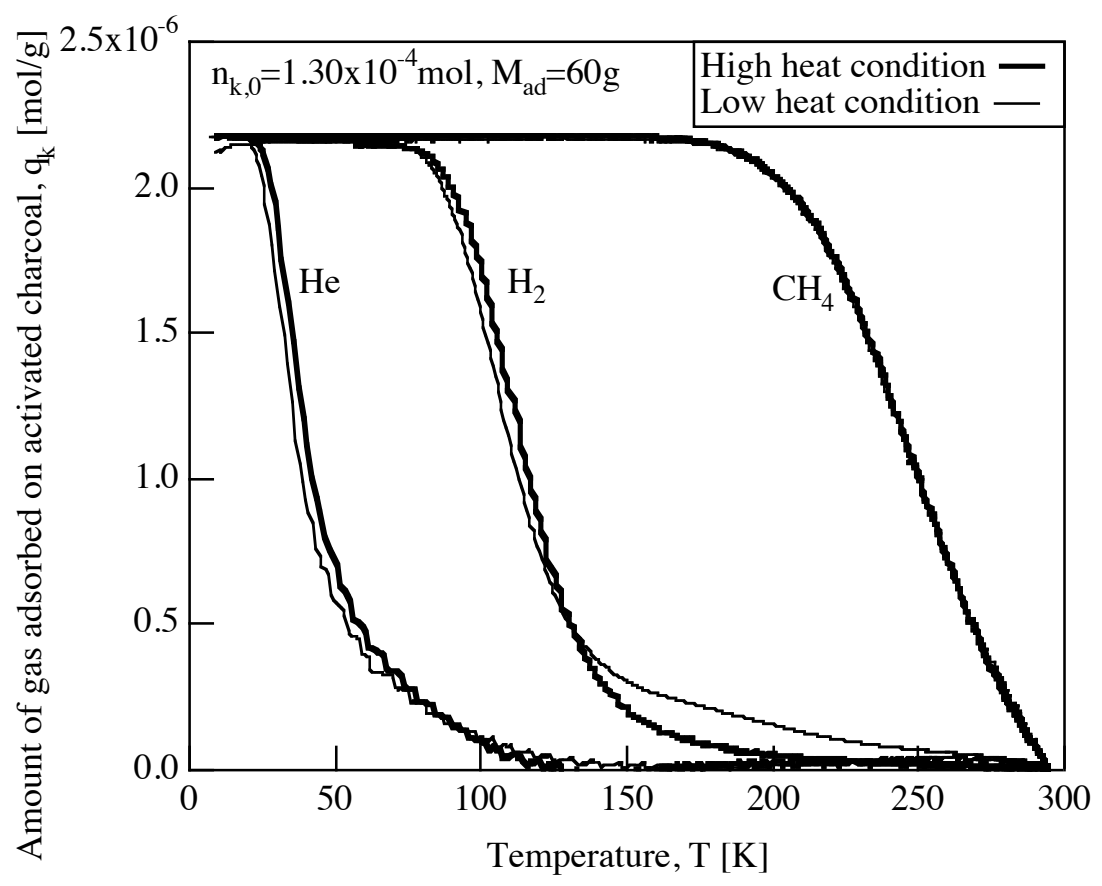

Fig. 4 Gas desorption profiles from activated carbon for different heating conditions 


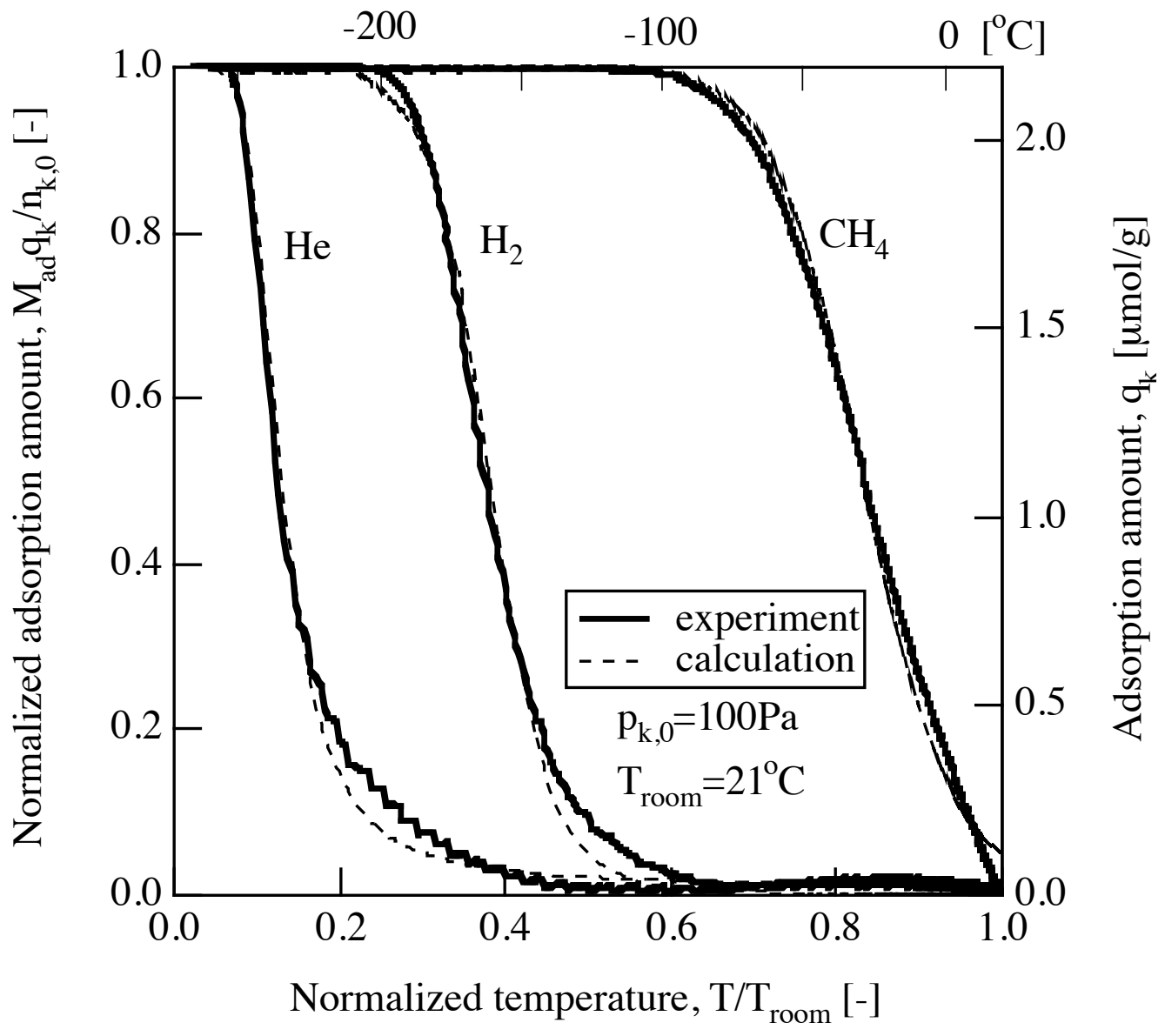

Fig. 5 Experimental desorption profiles for $\mathrm{He}, \mathrm{H}_{2}$, and $\mathrm{CH}_{4}$ from activated carbon and curves calculated from Langmuir-Freundlich isotherm 


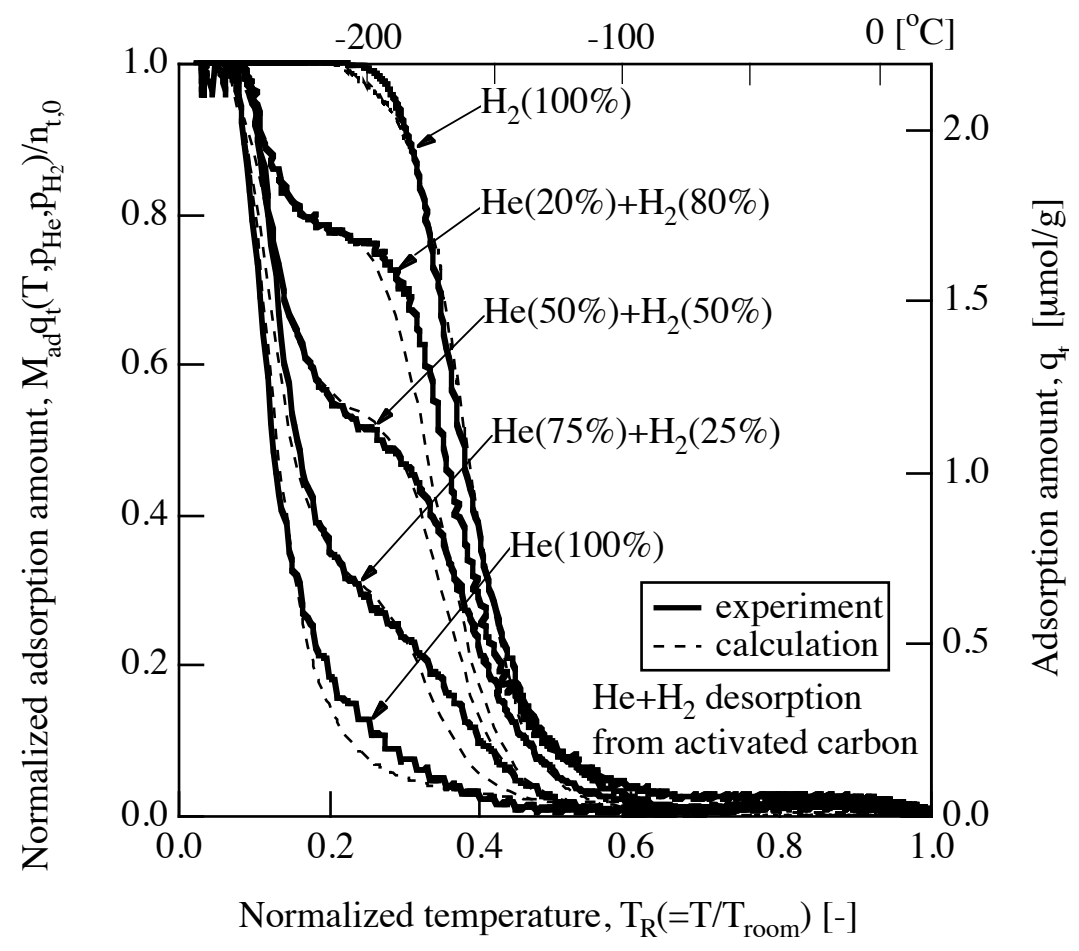

Fig. 6(a) Desorption of $\mathrm{H}_{2}+\mathrm{He}$ mixtures from activated carbon 


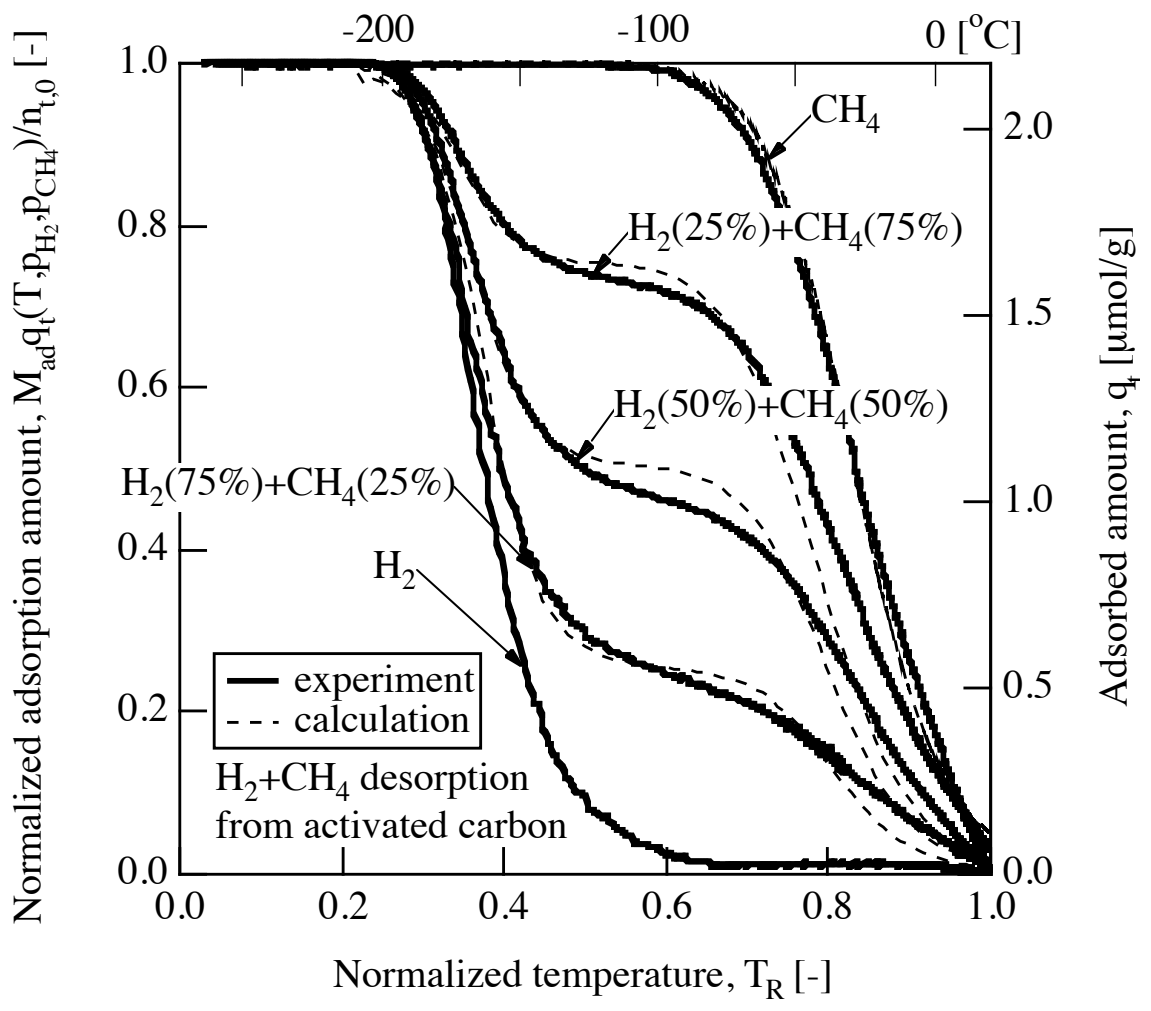

Fig. 6(b) Desorption of $\mathrm{He}+\mathrm{CH}_{4}$ mixtures from activated carbon 


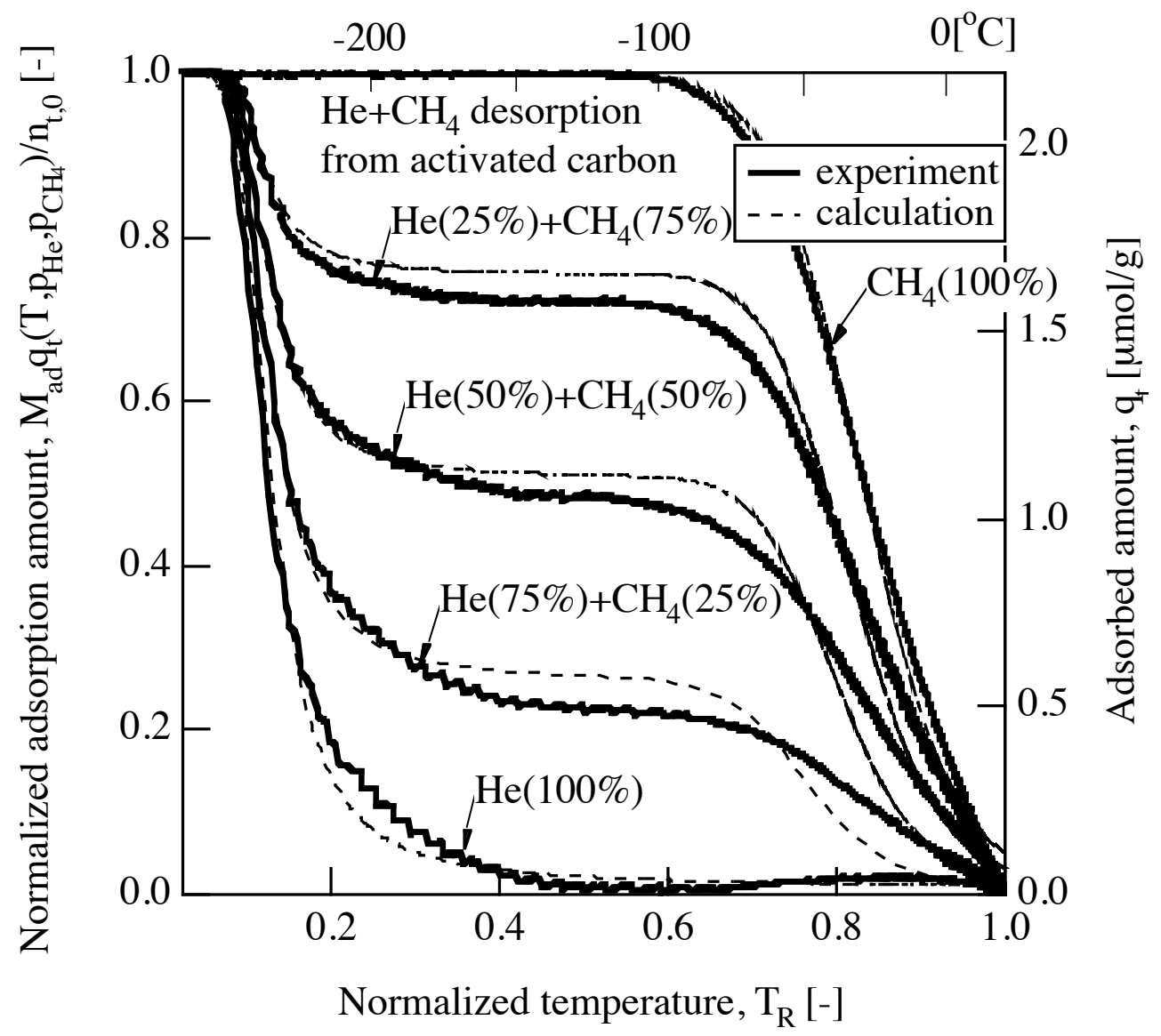

Fig. 6(c) Desorption of $\mathrm{H}_{2}+\mathrm{CH}_{4}$ mixtures from activated carbon 


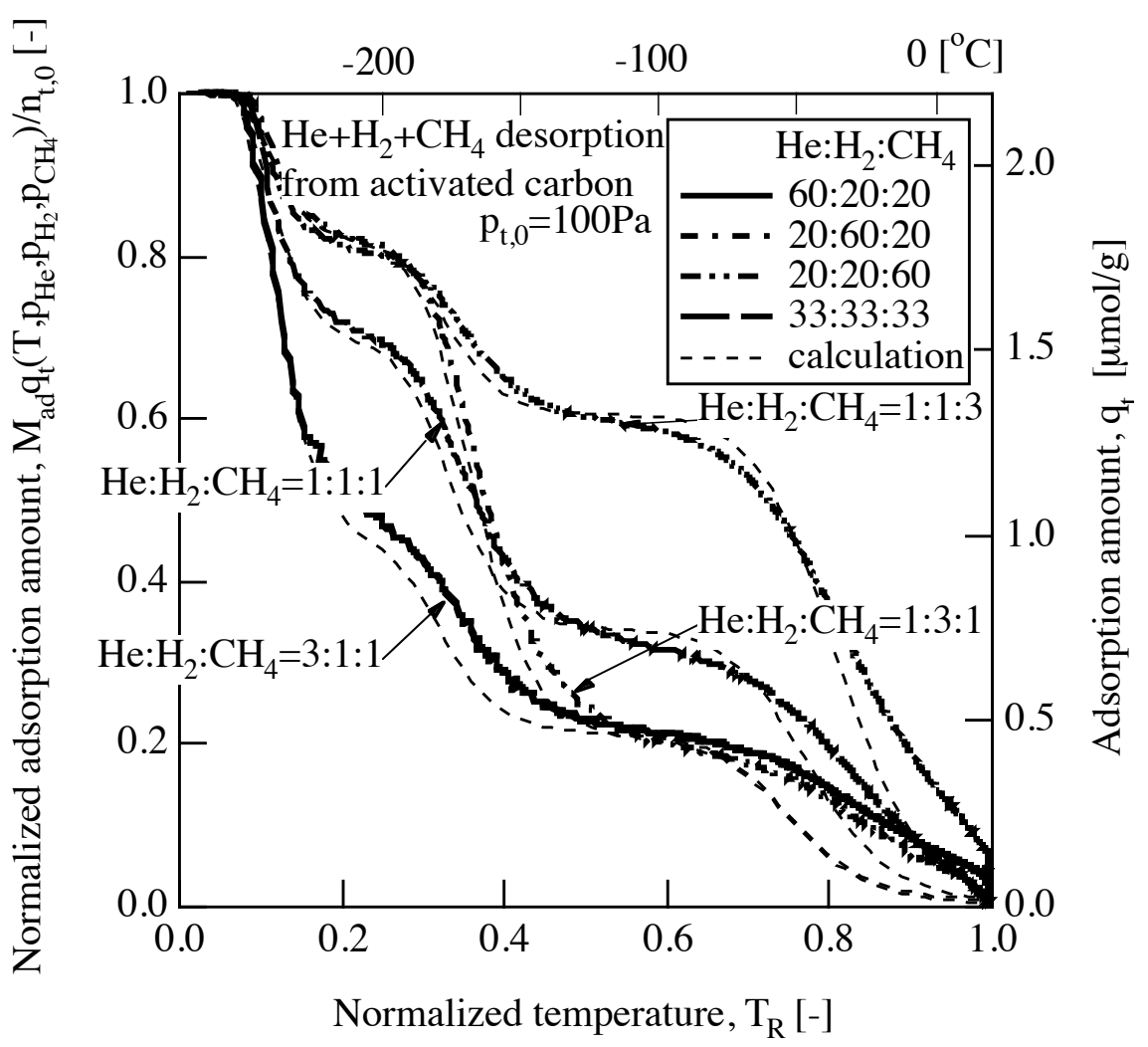

Fig. 7 Desorption of $\mathrm{He}+\mathrm{H}_{2}+\mathrm{CH}_{4}$ mixtures from activated carbon 


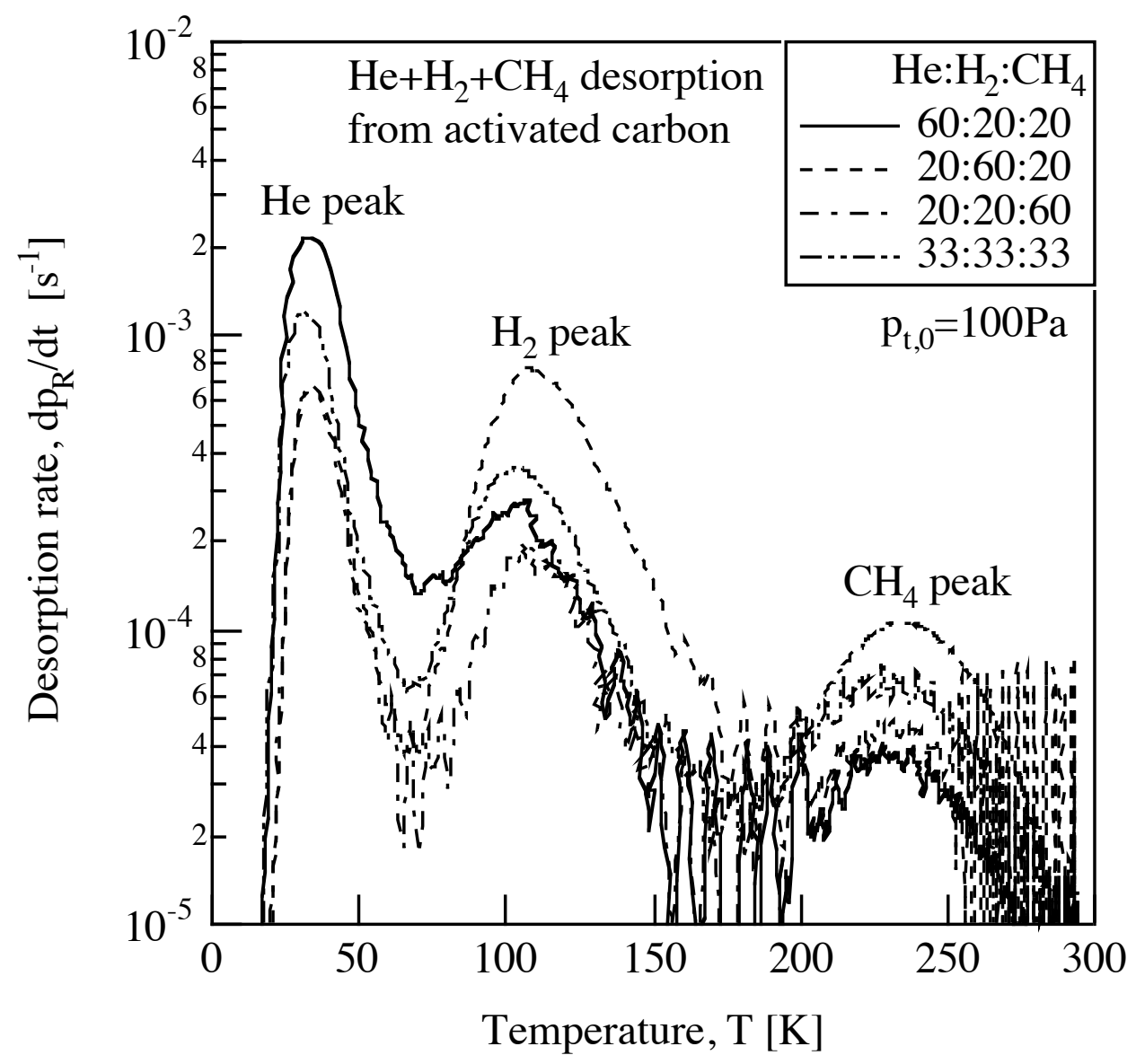

Fig. 8 Desorption rates of $\mathrm{He}, \mathrm{H}_{2}$ and $\mathrm{CH}_{4}$ mixtures from active carbon 


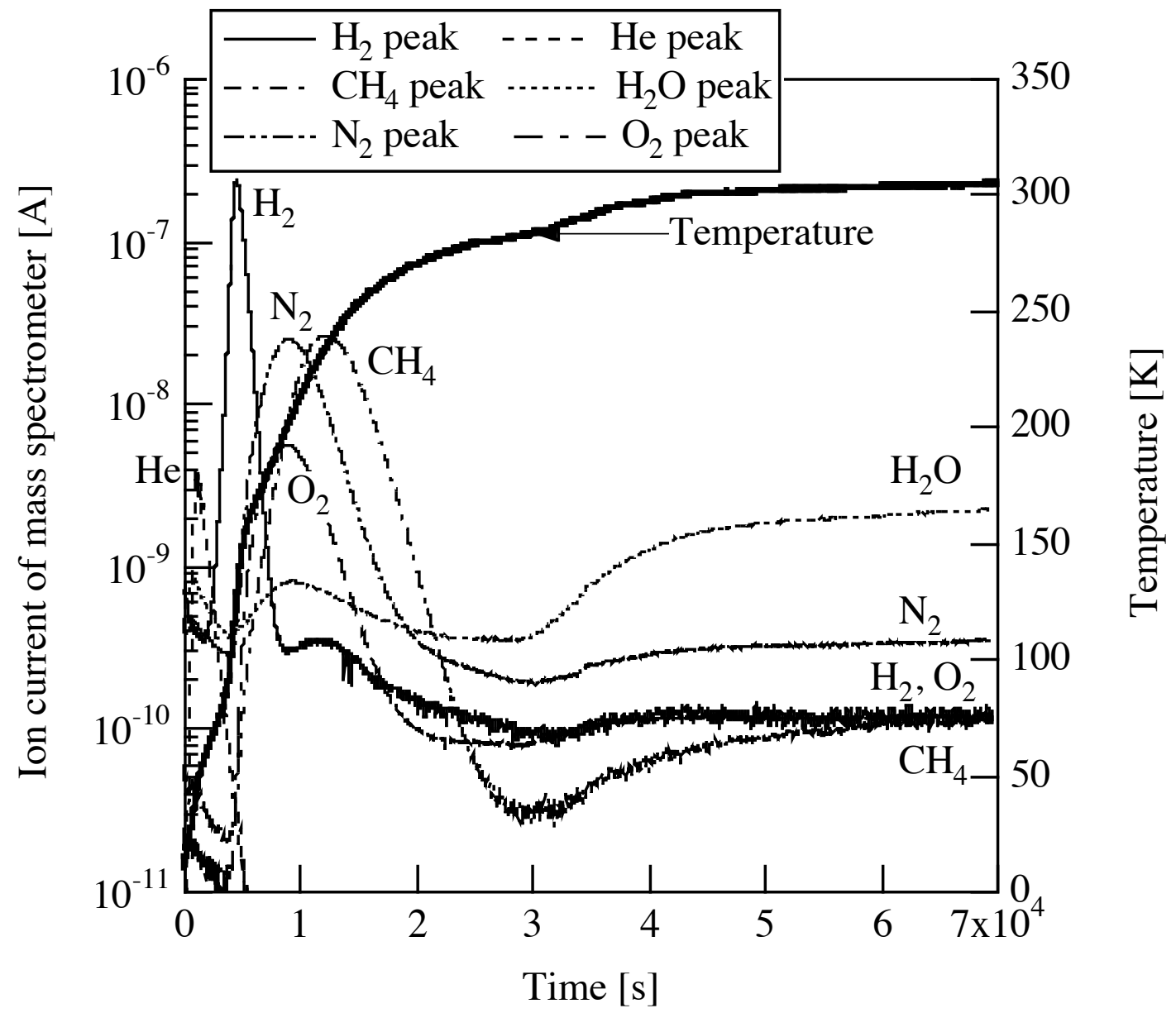

Fig. 9 Release of residual gas from activated carbon during heating 